\title{
OPQPal: (Gastroenterology \\ STUDY OF CLINICAL PROFILE OF PATIENTS WITH PANCREATIC ASCITES
}

\begin{tabular}{|c|}
\hline Dr M S Revathy \\
\hline $\begin{array}{l}\text { Dr Zameer } \\
\text { Ahamed S, MD* }\end{array}$ \\
\hline $\begin{array}{l}\text { Dr Sumathi B MD, } \\
\text { DM }\end{array}$ \\
\hline
\end{tabular}

Dr Chitra S MD, DM
Professor and Head of Department, Department of Medical Gastroenterology, Stanley medical College Chennai, Tamilnadu, India.

Resident Department Medical Gastroenterology Government Stanley Medical College, Chennai, India*Corresponding Author

Associate professor Department Medical Gastroenterology Government Stanley Medical College, Chennai, India

\section{Assistant Professor Department Medical Gastroenterology Government Stanley} Medical College, Chennai, India

ABSTRACT Background: Pancreatic diseases and their complications are common in the Indian Subcontinent. The exact prevalence of the pancreatic ascites is not known. Estimated prevalence is $3.5 \%$ in patients with chronic pancreatitis and $6 \%-14 \%$ in patients with pseudocyst. Aim: To study the clinical profile of patients with pancreatic ascitesand to identify the cause of patients with pancreatic ascites. Material and methods: Prospective, descriptive study. Consecutive patients with pancreatic ascites admitted between January 2018 and December 2019 were enrolled. Data retrieved included demographic, clinical profile and etiology of pancreatic ascites. Results: Total number of study subjects was 26 , majority were males (25/26), with mean age of 36.8 years. Most common symptom was abdominal pain and abdominal distension in 18 patients (69\%). Majority of patients had chronic pancreatitis (88.7\%). Alcohol is the most common etiology in 23 (88.7\%) patients. Conclusion: The results of our study suggests that the majority of patients with pancreatic ascites were having chronic pancreatitis with pseudocyst and alcohol consumption as a leading cause.

\section{KEYWORDS : Pancreatic ascites,chronic pancreatitis}

\section{INTRODUCTION}

Pancreatic diseases and their complications are common in the Indian Subcontinent. The exact prevalence of the pancreatic ascites is not known. Estimated prevalence is $3.5 \%$ in patients with chronic pancreatitis and $6 \%-14 \%$ in patients with pseudocyst ${ }^{1}$. The exact pathology varies considerably from patient to patient, unless patients are carefully investigated and treated, the mortality is $15-20 \%{ }^{2}$. The accumulation of ascitic fluid is caused by leakage of pancreatic juice through a pseudocyst or a disruption in the pancreatic duct which is secondary to chronic pancreatitis though it can occur rarely after acute pancreatitis or trauma

Pancreatic ascites is an exudative ascites caused by non-malignant disease of pancreas characterized by very high ascitic fluid amylase level over $1000 \mathrm{U} / \mathrm{L}$ protein concentration more than $3 \mathrm{gm} / \mathrm{dl}$ and in most cases the ascites is serous in nature, but it may be serosanguinous, turbid or chylous.It is for this reason that ascites in chronic pancreatitis deserves special consideration ${ }^{3}$ Hence study is conducted to look for the clinical profile and cause of pancreatic ascites in our centre

\section{AIMS AND OBJECTIVES}

1. To study the clinical profile of patients with pancreatic ascites.

2. To identify the cause of patients with pancreatic ascites.

\section{MATERIALS AND METHODS}

It was a Prospective, descriptivestudy,conducted in Department of Medical Gastroenterology, Govt.Stanley Medical College, Chennai,Tamil Nadu.All consecutive patients with pancreatic ascites admitted from January 2018 to December 2019 constituted the study cohort .There were 26 patients with pancreatic ascites, and their basic demographic profile, risk factors, clinical details and relevant investigations were noted in a pre-structured proforma after obtaining informed consent and Institutional Ethical Committee approval.

\section{STATISTICS AND DATAANALYSIS}

All data analysis was done using latest SPSS data analysis software, version 20.2 and descriptive statistics was presented as mean+ orstandard deviation and percentages. $\mathrm{P}<0.05$ was taken as significant

\section{RESULTS}

Total number of study subjects was 26 with male:female 25: 1 . Age distribution of cases ranged between $19-48$ years, with mean age of 36.8 years. Clinical symptoms included both abdominal pain and abdominal distension $(68 \%), 3$ cases abdominal distension $(12 \%)$ and 5 with abdominal pain alone $(19 \%)$ as the presenting symptoms. 23 cases had history of alcohol consumption $(88.7 \%)$ followed by trauma in 2 and idiopathic in 1 . Features of chronic pancreatitis was observed in 23 cases $(88.7 \%$ ) and 15 of them had pseudocyst and the remaining 3 cases had acute pancreatitis.10(38.4\%) patients responded to medical management, In $9(34.6 \%)$ patients ERCP pancreatic duct stenting was done and $7(26.9 \%)$ patients required surgery.Results were shown in table 1 .

Table 1

\begin{tabular}{|c|c|}
\hline Total number cases & 27 \\
\hline Male : Female & 26: 1 \\
\hline Clinical features & $\begin{array}{l}\text { Abdominal pain and abdominal distension- } \\
18(69 \%) \\
\text { Abdominal distension alone- } 3(12 \%) \\
\text { Abdominal pain alone - } 5(19 \%)\end{array}$ \\
\hline Types of pancreatitis & $\begin{array}{l}\text { Chronic pancreatitis with pseudocyst }-15 \\
(57.7 \%) \\
\text { Chronic pancreatitis- } 8(30.8 \%) \\
\text { Acute pancreatitis }-3(11.5 \%) \\
\end{array}$ \\
\hline Etiology & $\begin{array}{l}\text { Alcohol- } 23(88.7 \%) \\
\text { Trauma }-2(8 \%) \\
\text { Idiopathic }-1(4 \%)\end{array}$ \\
\hline Management & $\begin{array}{l}\text { Medical- } 10(38.4 \%) \\
\text { ERCP stenting- } 9(34.6 \%) \\
\text { Surgery- } 7(26.9 \%)\end{array}$ \\
\hline
\end{tabular}

\section{DISCUSSION}

The first patient with pancreatic ascites were reported in the early 1950 's followed by sporadic cases. In 1967 Cameron et $\mathrm{al}^{4}$ in a review reported 13 cases from the literature but established simple criteria for its diagnosis.Smith ${ }^{5}$ was the first to describe pancreatic ascites in patients with chronic pancreatitis. In 1976 Sankaran and Walt ${ }^{6}$ reported a series of 26 patients with pancreatic ascites seen at Wayne State University over a 17 -year period. They stated that $15 \%$ of all patients seen at their institution with pseudocysts had concomitant pancreatic ascites.

In 1976 Cameron et al ${ }^{4}$ reported a series from the Johns Hopkins Medical Institutions, seen over a 10 -year period.

In our study we had total of 26 subjects over a period of 1 year and majority were males which was similar to Cameron $\mathrm{J}$ et al series ${ }^{4}$. 
Mean age of the patients in our study was 36.8 years as compared to Gunturi SRV et $\mathrm{al}^{3}$ (41 years) and Sudhir Gupta, Nitin Gaikwad et $\mathrm{al}^{1}$ (43 years). Most common clinical presentation in our study was abdominal pain and abdominal distension in $69 \%$ of patients.

In the study by Cameron $\mathrm{Jet}^{4}{ }^{4}$ abdominal distension is most common symptom in patients with pancreatic ascites. In a study by Gunturi SRV et $\mathrm{al}^{3}$ and study by Sankaran and Walt ${ }^{6}$ on pancreatic ascites, abdominal distension was most common clinical feature.

In our study. Alcohol was the most commonaetiology in patients with pancreatic ascites constituting $88.7 \%$ of patients. (Consumption of alcohol for more than 8 years was noted)similar to study by Gunturi SRV etal ${ }^{3}$,Cameron $\mathrm{J}$ et al series and A Bracher, A Manocha, J DeBanto et $\mathrm{al}^{7}$.

In our study $57 \%$ of patients with pancreatic ascites had chronic pancreatitis with pseudocyst as compared to $34 \%$ by Gunturi SRV et $\mathrm{al}^{3}, 40-80 \%$ by Ramalingam Durai Rajan Somasekar et al ${ }^{8}$ and $70 \%$ by Sankaran and Walt. ${ }^{6}$

The aetiology in approximately $80 \%$ of cases is leakage or rupture of a pancreatic pseudocyst communicating with a ductal disruption ${ }^{\text {? }}$ Pancreatic duct disruptions in the face of inflammatory pancreatic disease are common. Often, however, they occur during an attack of acute pancreatitis ${ }^{4}$. A walling off of the ductal leak by the back wall of the stomach, the transverse colon and mesocolon, and other adjacent structures and organs. This walling off results in a pseudocyst. Occasionally, however, such a duct disruption occurs in the face of chronic inflammatory pancreatic disease, in the absence of acute inflammation $^{4}$

If the duct disruption is anterior, an internal pancreatic fistula into the peritoneal cavity is formed and pancreatic secretions flow freely into the abdomen. In as much as the enzymes are not activated, an acute peritonitis does not occur and painless ascites results, however sometimes peritoneal irritation does occur ${ }^{4}$.

In this same setting, if the duct disruption is posterior, the pancreatic secretions flow into the retroperitoneum,leading on to tracking along the path of least resistance, which usually is along the oesophagus or aorta up into the mediastinumpresenting as pleural effusion or mediastinal pseudocyst ${ }^{4}$.

A pancreatic ductal leak usually occurs as a complication of severe acute pancreatitis or underlying long standing chronic pancreatitis. The pathogenesis of duct disruption leading to ascites formation includes pancreatic necrosis, severe inflammation or obstruction of the duct, rupture of a pseudocyst into the peritoneal cavity and relentless progression of chronic pancreatitis. ${ }^{4}$

Commonly used imaging modalities for pancreatic diseases are CT scan and MRCP which provide better delineation of the pancreatic duct. Treatment modalities for the pancreatic ascites include conservative medical approach, endoscopic pancreatic therapy and surgical approach.

Majority of the patients responded to medical management(10 patients), ERCP and stenting was done in 9 patients and rest required surgery

\section{CONCLUSION}

The results of our study suggests that the majority of patients with pancreatic ascites were having chronic pancreatitis with pseudocyst and alcohol consumption as a leading cause.

Funding-none

Conflict of interest -none

\section{REFRENCES}

1. Efficacy of Pancreatic Endotherapy in Pancreatic Ascites and Pleural Effusion Sudhir Gupta, Nitin Gaikwad *, Amol Samarth, Niraj Sawalakhe and Tushar Sankalecha Med. Gupta, Nitin Gaikwad *, Amol Samarth, Nir
Sci. 2017, 5, 6; doi:10.3390/medsci5020006

2. Endoscopic Treatment of Pancreatic Ascites Richard A. Kozarek, MD, Geoffrey C. Jiranek, MD, L. William Traverso, MD, Seattle, WashingtonThe American journal of surgery** volume 168 september 1994

3. Surgical management of pancreatic ascites International Surgery Journal Gunturi SRV et al. Int Surg J. $2017 \mathrm{Feb} ; 4(2): 564-570$

4. Chronic pancreatic ascites and pancreatic pleural effusions clinical trends and topics john l. cameron, gastroenterolcgy 74134-140, 1978 .

5. Smith, E.B. Hemorrhagic ascites and hemothorax associated with benign pancreatic disease. AMAArch. Surg. 1953, 67, 52-56. [CrossRef] [PubMed]

6. Pancreatic Ascites Recognition and Management Suryanarayanan Sankaran, MB BS, Alexander J. Walt, MB ChB Arch Surg- vol 111.1976.

7. Bracher, G.A.; Manocha, A.P.; DeBanto, J.R.; Gates, L.K.; Slivka, A.; Whitcomb, D.C.; Martin, S.P. Endoscopic pancreatic duct stenting to treat pancreatic ascites Gastrointest. Endosc. 1999, 49, 710-715. [CrossRef]

1. 8.Ramalingam Durai Rajan Somasekar et al., Primary Early Surgical Management of Pancreatic Ascites Complicating Chronic Pancreatitis Journal of Clinical and Diagnostic Research. 2018 Feb. 